\title{
Defining benefit threshold for extracorporeal membrane oxygenation in children with sepsis-a binational multicenter cohort study
}

Luregn J. Schlapbach ${ }^{1,2,3^{*}}$ (D), Roberto Chiletti ${ }^{4,5}$, Lahn Straney ${ }^{1,6}$, Marino Festa ${ }^{7,8}$, Daniel Alexander ${ }^{9}$, Warwick Butt ${ }^{5}$, Graeme MacLaren ${ }^{5,10}$ and on behalf of the Australian \& New Zealand Intensive Care Society (ANZICS) Centre for Outcomes \& Resource Evaluation (CORE) and the Australian \& New Zealand Intensive Care Society (ANZICS)

Paediatric Study Group

\begin{abstract}
Background: The surviving sepsis campaign recommends consideration for extracorporeal membrane oxygenation $(E C M O)$ in refractory septic shock. We aimed to define the benefit threshold of ECMO in pediatric septic shock.

Methods: Retrospective binational multicenter cohort study of all ICUs contributing to the Australian and New Zealand Paediatric Intensive Care Registry. We included patients $<16$ years admitted to ICU with sepsis and septic shock between 2002 and 2016. Sepsis-specific risk-adjusted models to establish ECMO benefit thresholds with mortality as the primary outcome were performed. Models were based on clinical variables available early after admission to ICU. Multivariate analyses were performed to identify predictors of survival in children treated with ECMO.
\end{abstract}

Results: Five thousand sixty-two children with sepsis and septic shock met eligibility criteria, of which 80 (1.6\%) were treated with veno-arterial ECMO. A model based on 12 clinical variables predicted mortality with an AUROC of 0.879 (95\% Cl 0.864-0.895). The benefit threshold was calculated as $47.1 \%$ predicted risk of mortality. The observed mortality for children treated with ECMO below the threshold was $41.8 \%$ ( 23 deaths), compared to a predicted mortality of $30.0 \%$ as per the baseline model ( 16.5 deaths; standardized mortality rate $1.40,95 \% \mathrm{Cl} 0.89-$ 2.09). Among patients above the benefit threshold, the observed mortality was $52.0 \%$ (13 deaths) compared to $68.2 \%$ as per the baseline model (16.5 deaths; standardized mortality rate $0.61,95 \% \mathrm{Cl} 0.39-0.92$ ). Multivariable analyses identified lower lactate, the absence of cardiac arrest prior to ECMO, and the central cannulation (OR 0.31, $95 \% \mathrm{Cl} 0.10-0.98, p=0.046$ ) as significant predictors of survival for those treated with VA-ECMO.

Conclusions: This binational study demonstrates that a rapidly available sepsis mortality prediction model can define thresholds for survival benefit in children with septic shock considered for ECMO. Survival on ECMO was associated with central cannulation. Our findings suggest that a fully powered RCT on ECMO in sepsis is unlikely to be feasible.

Keywords: Childhood, Extracorporeal life support, Extracorporeal membrane oxygenation, Infection, Mortality, Pediatric, Prediction, Sepsis, Septic shock

\footnotetext{
* Correspondence: I.schlapbach@uq.edu.au

'Paediatric Critical Care Research Group, Child Health Research Centre, The

University of Queensland, Brisbane, Australia

${ }^{2}$ Paediatric Intensive Care Unit, Queensland Children's Hospital, South

Brisbane, QLD 4101, Australia

Full list of author information is available at the end of the article
}

(c) The Author(s). 2019 Open Access This article is distributed under the terms of the Creative Commons Attribution 4.0 International License (http://creativecommons.org/licenses/by/4.0/), which permits unrestricted use, distribution, and reproduction in any medium, provided you give appropriate credit to the original author(s) and the source, provide a link to the Creative Commons license, and indicate if changes were made. The Creative Commons Public Domain Dedication waiver (http://creativecommons.org/publicdomain/zero/1.0/) applies to the data made available in this article, unless otherwise stated. 


\section{Background}

Mortality in pediatric septic shock remains as high as $21 \%$ in pediatric intensive care units (PICU) [1-3]. In a substantial proportion of patients, shock will persist despite initial fluid resuscitation followed by vasoactive support as recommended by the Surviving Sepsis Campaign (SSC) [4] and the American College of Critical Care Medicine (ACCM) [5] guidelines. Refractory septic shock is characterized by profound circulatory dysfunction with alterations in myocardial function, vasoplegia, and failure of oxygen delivery to tissues, resulting in lactic acidosis [6, 7] and multi-organ failure, and accounts for most early sepsis deaths in children $[8,9]$.

Because extracorporeal membrane oxygenation (ECMO) can re-establish oxygen delivery in refractory shock, sepsis treatment guidelines have recommended consideration for its use as an adjunctive rescue therapy $[4,5]$. This recommendation originated from case reports and retrospective series suggesting potential survival benefit [10-20]. However, these observational data were based on highly selected cohorts of single institutions and lacked adjustment for severity of illness. Currently, patient selection remains determined by individual and institutional practice rather than objective criteria. There is an unmet need for models defining the benefit threshold of ECMO in pediatric sepsis.

We have previously developed a pediatric sepsis score [21] in critically ill children with sepsis admitted to ICUs, which predicted sepsis mortality using a simple set of criteria available within $1 \mathrm{~h}$ of ICU admission. We aimed to adapt this approach to define risk-adjusted benefit thresholds for ECMO in sepsis. We hypothesized that rapid mortality prediction in pediatric sepsis can identify patients likely to benefit if treated with ECMO.

\section{Methods}

We performed a multicenter binational retrospective cohort study of patients with sepsis and septic shock reported to the Australian and New Zealand Paediatric Intensive Care (ANZPIC) Registry [22]. The study was approved by the Human Research and Ethics Committee (Mater Health Services HREC, Brisbane, Australia) including waiver of informed consent. The ANZPIC registry prospectively records admissions of patients $<16$ years to specialized PICUs and mixed ICUs in Australia and New Zealand [1].

\section{Inclusion criteria}

Patients with age below 16 years that were non-electively admitted to a PICU or a general ICU in Australia and New Zealand between January 1, 2002, and December 31 , 2016, with sepsis or septic shock at ICU admission were eligible. Patients were required to have sepsis or septic shock (including toxic shock) as the principal diagnosis, the underlying diagnosis of ICU admission, or as a high-risk diagnosis [23]. In addition, we included patients if they had any invasive infection (including meningitis, pneumonia/pneumonitis, peritonitis, necrotizing fasciitis, osteomyelitis, endocarditis, tracheitis, epiglottitis) as the principal or the underlying diagnosis and also had sepsis and/or septic shock (including toxic shock) in any other diagnostic field.

Controls were defined as patients $<16$ years with sepsis and septic shock as defined above, which did not receive any ECMO.

We identified patients that underwent treatment with ECMO in the ANZPIC registry and manually checked these against the institutional ECMO databases of the six centers which provided ECMO during the study period. We checked the institutional ECMO databases and patient charts for the indications for ECMO and type of cannulation. Only veno-arterial (VA)-ECMO runs that were initiated to treat cardiovascular or combined cardiorespiratory failure in septic shock defined as per the 2005 International Pediatric Sepsis Consensus Conference [23] in patients who required inotropes prior to ECMO initiation and/or extracorporeal cardiopulmonary resuscitation (ECPR) were included as cases. Details on physiology upon initiation of ECMO, cannulation mode, and patient flow rates at $4 \mathrm{~h}$ post ECMO initiation were extracted from the institutional ECMO databases.

\section{Outcomes and definitions}

The primary outcome was defined as ICU mortality. ICU mortality and ICU length of stay were available for $100 \%$ of patients. Patient comorbidities were extracted from the diagnostic coding in the registry as described elsewhere [1, 21]. The Pediatric Index of Mortality 2 (PIM2) [24] was used to assess patient illness severity at ICU admission.

\section{Statistics (Additional file 1)}

Data are presented as percentages and numbers or medians with interquartile range (IQR). Two-sample Wilcoxon rank-sum (Mann-Whitney) tests were used to compare subgroups.

We previously demonstrated the high performance of a set of easily available clinical variables to predict sepsisrelated mortality in critically ill children within $1 \mathrm{~h}$ of ICU admission [1]. We optimized this sepsis-specific mortality prediction model using a stepwise logistic regression approach in the dataset restricted to septic patients which were not treated with VA-ECMO, including additional variables on treatment delivered during admission. The mortality prediction model included patient characteristics (age, interhospital transfer, immunosuppression), physiological parameters (arterial hypotension, $\mathrm{PaO}_{2} / \mathrm{FiO}_{2}$ ratio, lactate), clinical characteristics (presence of shock on 
admission, dilated unresponsive pupils, cardiac arrest prior to admission), and treatment interventions (ventilation during the first hour of admission; intubation; continuous renal replacement therapy; high-frequency oscillation ventilation (HFOV), and inhaled nitric oxide). We defined arterial hypotension as systolic blood pressure below the 5th percentile for age and sex as previously described [25]. We used all variables significantly associated with the primary outcome in univariable analyses to develop the multivariable models. This "naive" baseline risk adjustment model was built using only those patients who did not receive ECMO as part of their treatment. Reverse stepwise regression was used to select final covariates with exit criteria of $p<0.2$. We applied the Hosmer-Lemeshow goodness of fit test to assess calibration of the model in septic patients not treated with ECMO and described the area under the curve of receiver-operating-characteristic (AUROC) curve analysis. This disease-specific prediction model was then used for every patient (both septic controls and ECMO cases) to calculate the predicted mortality based on patient characteristics, severity upon presentation to intensive care, and level of support. We then used the linear prediction of the baseline risk adjustment model as a covariate in a second-stage model, the "treatment model," to evaluate the effect of ECMO on ICU mortality for children with sepsis and septic shock. We estimated this second-stage model using a bootstrap procedure with 1000 repetitions. The samples were the same size as the total dataset and drawn with replacement from the original data stratified by ECMO treatment. The coefficients from each model repetition were used to estimate a distribution for the benefit threshold. The median was used to estimate the estimated threshold in baseline risk for benefit, and the 2.5th and 97.5th percentiles were used to estimate uncertainty intervals. This second-stage model was then repeated as a sensitivity analysis in only those patients coded with septic shock.

To analyze factors associated with survival of those children treated with ECMO for septic shock, we performed univariable followed by backward stepwise logistic regression including covariates with exit criteria of $p<0.2$.

All analyses were conducted using Stata (version 15.0, Stata Corp, College Station, TX, USA).

\section{Results}

\section{Cohort description}

During the study period, 5062 children coded as sepsis and septic shock met the eligibility criteria, of which 80 (1.6\%) were treated with ECMO for septic shock, which was confirmed using manual checking of patient records (Table 1$)$. The crude mortality was $10.6 \%(483 / 4982)$ in controls and $45.0 \%(36 / 80)$ in ECMO cases $(p<0.001)$. The median time from ICU admission to death was 53.0 h (IQR 15.2-189.2, Additional file 2). In 61.3\% (49/80) of ECMO cases and 45.2\% (2250/4982) of controls, a bacterial pathogen was identified (Additional file 3). Patients treated with ECMO for septic shock were more likely to have undergone interhospital transfer and were sicker on admission to PICU as evidenced by lower systolic blood pressure, higher lactate, and higher PIM-2 scores. The proportion of children with sepsis treated with ECMO during the study period did not change substantially (14.2 ECMO-treated children per 1000 pediatric sepsis admissions in 2002-2009 compared with $17.0 / 1000$ in 2010-2017, $p=0.425$ ). In the ECMO group, $13(16.3 \%)$ were diagnosed with ARDS, in comparison to $157(3.2 \%)$ of patients in the control group $(p<0.001)$. Nine $(11 \%)$ of the ECMO patients had undergone cannulation at a referring hospital.

\section{Predicted sepsis mortality}

The final multivariable model to predict ICU mortality in children with sepsis and septic shock admitted to ICU included severe respiratory failure $(\mathrm{PaO} 2 / \mathrm{FiO} 2$ ratio, intubation, and treatment with HFOV); shock or cardiac arrest (arterial hypotension, shock on presentation, cardiac arrest pre ICU admission); metabolic (high lactate), central nervous system (dilated pupils), and renal (need for renal replacement) dysfunction; and underlying immunosuppression as significant predictors (Table 2). The model was well calibrated (Hosmer-Lemeshow goodness-of-fit test chi-square 9.83, $p=0.277$ ) and predicted mortality with an AUROC of 0.879 (95\% CI 0.864-0.895) which was significantly superior to mortality prediction using PIM-2 (AUROC 0.789; 0.765-0.813, $p<0.0001)$.

\section{Treatment benefit threshold}

The benefit threshold, defined as the baseline mortality risk generated by our predictive model for which ECMO was associated with increased survival was calculated as $47.1 \%$ risk of mortality $(95 \%$ CI $27.9-84.3 \%$, Fig. 1 and Additional file 5). Of the children who received ECMO, $31.3 \%$ (25) had a baseline risk above the benefit threshold. The observed mortality for children treated with ECMO below the threshold was $41.8 \%$ (23 deaths), compared to a predicted mortality of $30.0 \%$ as per the baseline model (16.5 deaths; standardized mortality rate 1.40, 95\% confidence interval 0.89-2.09). Among patients above the benefit threshold the observed mortality was $52.0 \%$ (13 deaths) compared to $68.2 \%$ as per the baseline model (16.5 deaths; standardized mortality rate 0.61 , 95\% confidence interval 0.39-0.92). Sensitivity analyses restricted to patients coded as septic shock in the ANZPICR resulted similarly ( $n=80$ cases, $n=2347$ controls, benefit threshold of 47.7\%; 95\% CI 17.4-93.6\%) (Additional file 6). 
Table 1 Baseline characteristics and severity characteristics in 5062 children admitted to intensive care units with sepsis and septic shock compared between children receiving extracorporeal membrane oxygenation (ECMO) and controls (no ECMO)

\begin{tabular}{|c|c|c|c|c|}
\hline \multirow[t]{2}{*}{ Characteristic } & \multirow[t]{2}{*}{ Variable } & \multirow{2}{*}{$\begin{array}{l}\text { Sepsis or septic shock on } \\
\text { admission-control group } \\
\text { (no ECMO) } \\
N=4982\end{array}$} & \multicolumn{2}{|c|}{$\begin{array}{l}\text { Sepsis or septic shock on admission- } \\
\text { ECMO group }\end{array}$} \\
\hline & & & $n=80$ & $p$ value $^{a}$ \\
\hline Age & Age (days), median (IQR) & $598.5(103,2588)$ & $463(44,2546)$ & 0.48 \\
\hline \multirow[t]{4}{*}{ Age group } & Infants (birth to 364 days) & $2671(53.6 \%)$ & $45(56.3 \%)$ & 0.95 \\
\hline & $1-4$ years & $915(18.4 \%)$ & $14(17.5 \%)$ & \\
\hline & $5-9$ years & $874(17.5 \%)$ & $14(17.5 \%)$ & \\
\hline & 10-15 years & $522(10.5 \%)$ & $7(8.8 \%)$ & \\
\hline Indigenous status & Indigenous or Torres Strait Islander & $411(11.8 \%)$ & $4(6.0 \%)$ & 0.14 \\
\hline \multirow[t]{3}{*}{ Demographics } & $\%$ male & 2835 (56.9\%) & $49(61.3 \%)$ & 0.44 \\
\hline & Weight, median (IQR) & $11.1(5.2,23.0)$ & $10.55(3.85,25.0)$ & 0.79 \\
\hline & Interhospital transfer & $1846(37.1 \%)$ & $53(66.3 \%)$ & $<0.001$ \\
\hline \multirow[t]{3}{*}{ Comorbidities } & Congenital heart disease & $288(5.8 \%)$ & $8(10.0 \%)$ & 0.11 \\
\hline & Immunosuppression ${ }^{\mathrm{b}}$ & $801(16.1 \%)$ & $7(8.8 \%)$ & 0.076 \\
\hline & Oncology & $733(14.7 \%)$ & $4(5.0 \%)$ & 0.015 \\
\hline \multirow[t]{5}{*}{ Severity on PICU admission ${ }^{c}$} & Shock on admission & $2347(47.1 \%)$ & $72(90.0 \%)$ & $<0.001$ \\
\hline & Systolic blood pressure, median (IQR) & $93(80,108)$ & $85(56,100)$ & $<0.001$ \\
\hline & Lactate, median (IQR) & $3.26(3.26,3.26)$ & $4.95(3.26,8.05)$ & $<0.001$ \\
\hline & Dilated unresponsive pupils & $45(0.9 \%)$ & $2(2.5 \%)$ & 0.14 \\
\hline & Cardiac arrest pre-admission & $61(1.2 \%)$ & $13(16.3 \%)$ & $<0.001$ \\
\hline \multirow[t]{6}{*}{ Therapy } & Intubated & $2537(51.2 \%)$ & $80(100.0 \%)$ & $<0.001$ \\
\hline & Mechanical ventilation in the first hour & $2049(41.2 \%)$ & $68(85.0 \%)$ & $<0.001$ \\
\hline & Inotropes during 1st hour & $1053(30.0 \%)$ & $57(76.0 \%)$ & $<0.001$ \\
\hline & Renal replacement & $200(4.0 \%)$ & $41(51.2 \%)$ & $<0.001$ \\
\hline & High-frequency oscillation ventilation & $180(3.6 \%)$ & $21(26.3 \%)$ & $<0.001$ \\
\hline & Inhaled nitric oxide & $130(2.6 \%)$ & $23(28.7 \%)$ & $<0.001$ \\
\hline \multirow[t]{5}{*}{ Outcome measures } & PIM2, mean (SD) & $0.08(0.14)$ & $0.25(0.29)$ & $<0.001$ \\
\hline & PIM2, median (IQR) & $0.03(0.01,0.07)$ & $0.13(0.04,0.35)$ & $<0.001$ \\
\hline & Hospital mortality & $501(10.9 \%)$ & $36(45.0 \%)$ & $<0.001$ \\
\hline & ICU mortality & $415(8.3 \%)$ & $36(45.0 \%)$ & $<0.001$ \\
\hline & Mean PICU length of stay (hours), median (IQR) & $56.65(23.33,135.77)$ & $240.28(59.28,452.79)$ & $<0.001$ \\
\hline \multirow[t]{3}{*}{ Pathogen } & Sum of patients with bacterial diagnosis & $2250(45.2 \%)$ & $49(61.3 \%)$ & 0.004 \\
\hline & Viral coinfection & $532(10.7 \%)$ & $10(12.5 \%)$ & 0.60 \\
\hline & No bacterial, fungal, or viral organism identified & $2367(47.5 \%)$ & $25(31.3 \%)$ & 0.004 \\
\hline
\end{tabular}

PICU pediatric intensive care unit, PIM2 Pediatric Index of Mortality 2

${ }^{a} p$ value based on two-sample Wilcoxon rank-sum (Mann-Whitney) test

befined as either primary immunodeficiency or secondary immunodeficiency, including bone marrow transplants, oncology patients under active treatment, other solid organ transplant patients, and systemic immunosuppression such as for rheumatologic disease

'First observation, the measure must be obtained within the first $60 \mathrm{~min}$ of PICU admission

Based on these figures, we estimate that a future trial on ECMO in pediatric septic shock would require enrolment of at least 143 children treated with ECMO with baseline risk above the threshold to detect a mortality difference of $16.2 \%$ ( $52 \%$ versus $68.2 \%$ ) with a power of $80 \%$ and a two-sided significance level of 0.05 . Such a trial would need to screen approximatively 300,000 children admitted to ICU with sepsis and septic shock in our population.

\section{ECMO survivors versus ECMO fatal cases}

Crude mortality in the 80 patients treated with VAECMO for septic shock was 45\% (36/80) (Table 3 and Additional file 4). Thirty-two (40\%) suffered a cardiac 
Table 2 Uni- and multivariable prediction models for ICU mortality in 5062 children admitted to intensive care units with sepsis and septic shock

\begin{tabular}{|c|c|c|c|c|c|}
\hline \multicolumn{2}{|c|}{ Predictor variable } & \multicolumn{2}{|l|}{ Univariable model } & \multicolumn{2}{|l|}{ Multivariable model } \\
\hline Group & Predictor & OR $(95 \% \mathrm{Cl})$ & $p$ value & OR $(95 \% \mathrm{Cl})$ & $p$ value \\
\hline \multirow[t]{5}{*}{ Respiratory } & $\mathrm{PaO} 2 / \mathrm{FiO} 2$ ratio & $2.83(2.34-3.43)$ & $<0.001$ & $1.57(1.28-1.91)$ & $<0.001$ \\
\hline & Ventilation during the first hour & $3.97(3.15-4.96)$ & $<0.001$ & NS & \\
\hline & Intubated & $23.19(14.58-36.89)$ & $<0.001$ & $15.92(9.76-25.96)$ & $<0.001$ \\
\hline & High frequency ventilation & $7.59(5.50-10.46)$ & $<0.001$ & $2.26(1.48-3.45)$ & $<0.001$ \\
\hline & Inhaled nitric oxide & $7.15(4.93-10.37)$ & $<0.001$ & NS & \\
\hline \multirow[t]{3}{*}{ Circulatory } & SBP $<5$ th percentile & $3.06(2.45-3.82)$ & $<0.001$ & $1.81(1.39-2.36)$ & $<0.001$ \\
\hline & Cardiac arrest pre-admission & $6.50(3.82-11.07)$ & $<0.001$ & $2.36(1.23-4.52)$ & 0.01 \\
\hline & Shock on presentation & $4.78(3.73-6.07)$ & $<0.001$ & $2.31(1.76-3.04)$ & $<0.001$ \\
\hline Metabolic & Lactate $(\mathrm{mmol} / \mathrm{l})$ & $1.26(1.20-1.32)$ & $<0.001$ & $1.12(1.07-1.18)$ & $<0.001$ \\
\hline Renal & Renal replacement therapy & $8.23(6.06-11.17)$ & $<0.001$ & $2.44(1.72-3.47)$ & $<0.001$ \\
\hline Neurologic & Dilated, unresponsive pupils & $48.11(23.00-11,062)$ & $<0.001$ & $35.01(15.35-79.84)$ & $<0.001$ \\
\hline Patient & Immunosuppression & $1.65(1.29-2.10)$ & $<0.001$ & $2.66(1.95-3.63)$ & $<0.001$ \\
\hline
\end{tabular}

$O R$ odds ratio, $\mathrm{Cl}$ confidence interval, SBP systolic blood pressure

arrest prior to ECMO including 18 (23\%) patients treated with ECPR for sepsis-related cardiac arrest. Fiftyseven out of 80 (71\%) underwent primary open-chest cannulation in comparison to $23 / 80$ (29\%) who were initially cannulated peripherally. The median time from ICU admission to ECMO cannulation was $7 \mathrm{~h}$ in ECMO survivors compared to $2.8 \mathrm{~h}$ in ECMO deaths $(p=0.13)$. Children treated with ECMO who survived had lower admission lactate and PIM2 scores, higher $\mathrm{pH}$ and bicarbonate pre-ECMO, and a lower proportion with cardiac arrest prior to ECMO and were more often cannulated centrally. While the flow rates measured at $4 \mathrm{~h}$ were not significantly different between ECMO survivors and fatalities (Additional file 7), the mean flow rates of children cannulated centrally were $173 \mathrm{ml} / \mathrm{kg} / \mathrm{min}$ in comparison to $129 \mathrm{ml} / \mathrm{kg} / \mathrm{min}$ in children cannulated peripherally $(p<0.05)$. Multivariable analyses confirmed that higher lactate (odd's ratio 1.21, 95\%CI 1.04-1.40, $p=0.012$ ), cardiac arrest prior to ECMO (OR 4.59, 1.5813.10, $p=0.005$ ) and central cannulation (OR 0.31, $0.10-0.98, p=0.046)$ were significant independent predictors of mortality (Table 4, AUC 0.776).

\section{Discussion}

Up to $50 \%$ of pediatric sepsis deaths occur within the first $24 \mathrm{~h}$ of admission [8, 21, 26, 27], predominantly because of refractory shock with circulatory failure. Any hypothetical novel intervention in sepsis would need to be applied within a few hours of PICU admission, and result in rapid physiologic improvement to yield any chance of major survival benefit. Such pharmacological interventions are not in sight; in contrast, mechanical circulatory support can be provided within a short time frame and can result in immediate improvement of circulatory status, but exposes patients to substantial, potentially life-threatening side effects. In this binational cohort including critically ill children with sepsis and septic shock, we demonstrated that a mortality prediction model based on 12 clinical variables allows discrimination of patients more likely to have treatment benefit from VA-ECMO therapy. To the best of our knowledge, this is the first study to assess benefit threshold of ECMO in sepsis, and the largest and only populationbased study to report on risk-adjusted outcomes of ECMO in pediatric sepsis. Multivariable analyses identified lower lactate, absence of a cardiac arrest prior to ECMO, and central cannulation as independent protective factors for survival in children treated with ECMO for septic shock.

We identified a predicted mortality of $47.1 \%$ as the threshold above which ECMO was likely beneficial for children with septic shock. In children with lower disease-specific predicted mortality, the potential for harm may outweigh benefits related to ECMO. ECMO was initiated within the first few hours of PICU admission in the majority of children with refractory septic shock, which supports the need for rapid outcome prediction based on a set of clinical parameters that can be assessed within the first hour of admission to PICU. Recent studies have highlighted the promise of relatively simple clinical tools to assist in prediction of ECMO treatment benefit versus expected mortality in patients with acute respiratory distress syndrome [28, 29]. Importantly, our model incorporates several variables that were identified as essential criteria for pediatric refractory septic shock, specifically lactate, and severe cardiovascular dysfunction [9]. Our model predicting sepsis mortality with an AUC of 0.879 was 


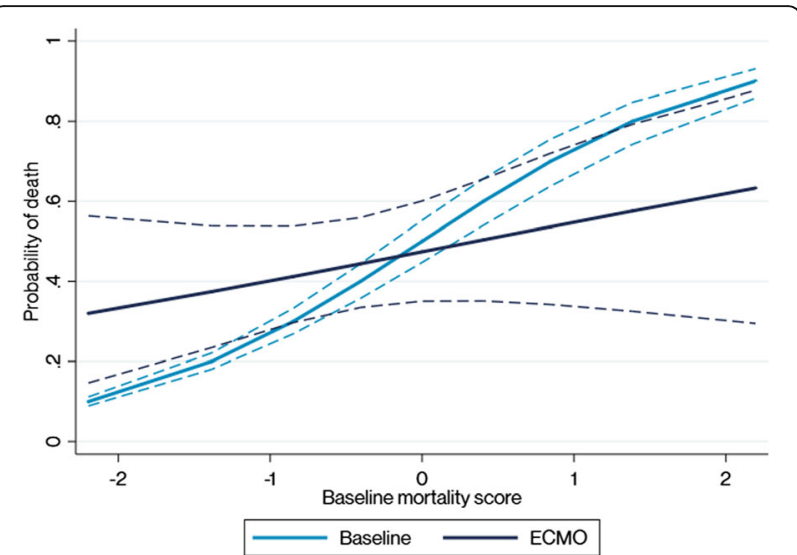

Fig. 1 Estimating treatment benefit for children with sepsis and septic shock treated with extracorporeal life support (ECMO) versus controls. The marginal mean for estimated mortality is shown ( $y$ scale) versus the baseline mortality score ( $x$-scale) for children treated with ECMO (dark blue line) versus controls (light blue line). Full lines indicate the effect estimate, and dashed lines indicate 95\% confidence intervals. The benefit threshold, defined as the baseline risk for which ECMO became beneficial, reflects the intersection of both lines at $47.1 \%$ predicted risk of mortality. The predicted mortality risk is adjusted for covariates on respiratory failure ( $\mathrm{PaO} 2 /$ $\mathrm{FiO} 2$ ratio, intubation, treatment with HFOV); cardiovascular (arterial hypotension, shock on presentation, cardiac arrest pre ICU admission), metabolic (high lactate), central nervous system (dilated pupils), and renal (need for renal replacement) dysfunction; and underlying immunosuppression. The naïve baseline risk model is given by $F 1$, where $p_{B}$ is the baseline probability of mortality estimated among non-treated patients, BRS is the Baseline Risk Score, $B_{0}$ is the intercept, and $B_{n}$ and $X$ represent a matrix of coefficients and risk factors. F1: $\operatorname{Logit}\left(p_{B}\right)=B R S=B_{0}+B_{n} X$. The treatment model is given by $F 2$, where $p_{D}$ is the estimated mortality rate, $B R S$ is the Baseline Risk Score (from F1), $B_{0}$ is the intercept, and ECMO is a binary treatment variable ( $1=y e s)$. The final term is an interaction term between treatment and the baseline risk score. F2: $\operatorname{Logit}\left(p_{\mathrm{D}}\right)=B_{0}+B_{1} \times B R S+B_{2} \times E C M O+B_{3} \times(E C M O * B R S)$

developed from the previously published sepsis score [21], which permitted much better disease-specific risk prediction that commonly used scores such as PIM or PRISM.

Refractory septic shock in neonates and children carries a very high mortality as demonstrated by a recent multicenter study [9], and survivors often suffer from disability related to limb loss and neurocognitive impairment $[2,9,30]$. While current sepsis treatment guidelines recommend use of ECMO as an adjunctive rescue therapy, these recommendations are based on highly selected small single-center reports which hinder generalizability $[10,12,14,31]$. In view of the rapidly expanding use of ECMO and an increasing number of adult and pediatric ECMO centers, there is an urgent need to understand the value of this therapy in sepsis. We here demonstrate proof of concept of a sepsisspecific survival prediction model which can enable appropriate resource use by early identification of patients most likely to benefit from ECMO. In addition, the model allows risk-adjusted comparison of ECMO outcomes for the purpose of benchmarking and quality control.

The largest series to date on children treated with ECMO for sepsis was based on the US Pediatric Health Information System database and suggested a significant increase in use of ECMO in recent years [32]. The mortality in this study was $47.8 \%$ for children who received any form of ECMO, which is comparable to our findings restricted to VA-ECMO for septic shock. While the US study was based on data from 43 PICUs participating in the Children's Hospital Association, representing approximatively $15 \%$ of US PICUs, our study was based on the Australian and New Zealand prospective pediatric ICU registry which captures admissions to all PICUs, including $100 \%$ of pediatric ECMO centers. A recent study assessed retrospective data on 164 children admitted to 7 PICUs in 5 countries with septic shock, including 44 VA-ECMO runs, and observed a reduced crude mortality in the subgroup of patients with cardiac arrest treated with ECMO [33]. Multivariable analyses identified high lactate and cardiac arrest as significant mortality predictors, and a possible association between higher ECMO flow rates and improved survival. This supports previous single-center series [10, 31, 34] suggesting substantial mortality reduction when using a protocolized approach including central cannulation with larger size cannulae to achieve higher ECMO flow rates, compared to historic controls, with survival to discharge as high as $74 \%$. The major limitation in these previous studies on ECMO in pediatric sepsis is the lack of risk-adjustment and failure to control for confounding by severity and indication.

Further validation in independent cohort is required to address several limitations of this study: First, ECMO and disease-specific outcomes may vary from site to site resulting in variable thresholds for treatment benefit. In addition, the use of central cannulation in non-cardiac surgery patients is something that may be more commonly used in Australian PICUs. Second, the study spanned across 15 years, and patient population, microbiology, and thresholds to initiate treatment may have changed [35]. While classic meningococcal shock associated with purpura fulminans has become rare, current septic shock phenotypes are often characterized by difficult source control, hypercoagulopathy, necrotizing pneumonia, and challenges related to host comorbidities including immunosuppression [36, 37]. Third, despite the fact that this is the largest study in the field, the inclusion of only 80 ECMO patients resulted in wide confidence intervals on treatment benefit thresholds. Fourth, due to the rapid dynamics of septic shock, repeat characterization and trend analysis of patient physiology several hours after PICU admission rather than within 
Table 3 Extracorporeal membrane oxygenation (ECMO) run characteristics of 80 children with sepsis and septic shock compared between children who survived and children that died

\begin{tabular}{|c|c|c|c|c|}
\hline \multirow[t]{2}{*}{ Characteristic } & \multirow[t]{2}{*}{ Variable } & \multirow{2}{*}{$\begin{array}{l}\text { Survived } \\
N=44(55 \%)\end{array}$} & \multirow{2}{*}{$\begin{array}{l}\text { Died } \\
N=36(45 \%)\end{array}$} & \multirow[t]{2}{*}{$p$ value } \\
\hline & & & & \\
\hline Age & Age (days), median (IQR) & $1241(36.5,2595.5)$ & $308.50(63.5,1272)$ & 0.19 \\
\hline \multirow[t]{6}{*}{ Severity on PICU admission ${ }^{b}$} & Systolic blood pressure, median (IQR) & $85(58,105)$ & $77(56,96)$ & 0.27 \\
\hline & Lactate, median (IQR) & $4.15(3.3,6.2)$ & $6.05(3.3,11.1)$ & 0.002 \\
\hline & Dilated unresponsive pupils & $1(2 \%)$ & $1(3 \%)$ & 0.89 \\
\hline & Cardiac arrest pre-admission & $6(14 \%)$ & $7(19 \%)$ & 0.48 \\
\hline & PIM2, mean (SD) & $0.19(0.26)$ & $0.32(0.31)$ & 0.052 \\
\hline & PIM2, median (IQR) & $0.09(0.04,0.21)$ & $0.22(0.06,0.51)$ & 0.033 \\
\hline \multirow[t]{6}{*}{ Therapy in PICU } & Intubated & $44(100 \%)$ & $36(100 \%)$ & NA \\
\hline & Mechanical ventilation during 1 st hour & $37(84 \%)$ & $31(86 \%)$ & 0.80 \\
\hline & Inotropes during 1st hour & $27(66 \%)$ & $30(88 \%)$ & 0.055 \\
\hline & Renal replacement & $27(61 \%)$ & $14(39 \%)$ & 0.045 \\
\hline & High-frequency oscillation ventilation & $11(25 \%)$ & $10(28 \%)$ & 0.78 \\
\hline & Inhaled nitric oxide & $14(32 \%)$ & $9(25 \%)$ & 0.50 \\
\hline \multirow[t]{14}{*}{ Pre-ECMO physiology } & CPR pre ECMO & $11(25 \%)$ & $21(58 \%)$ & 0.002 \\
\hline & pH, median (IQR) & $7.14(7.06,7.26)$ & $7.04(6.98,7.19)$ & 0.028 \\
\hline & pCO2, median (IQR) & $47(40,57)$ & $48(37,56)$ & 0.67 \\
\hline & pO2, median (IQR) & $58.5(40.5,111.5)$ & $77(43,128)$ & 0.53 \\
\hline & SaO2, median (IQR) & $90(71,96)$ & $94(86,98)$ & 0.19 \\
\hline & HCO3, median (IQR) & $17(13,23)$ & $14(9,18)$ & 0.027 \\
\hline & PIP/Amplitude, median (IQR) & $30(26,38.5)$ & $35(26,48)$ & 0.27 \\
\hline & PEEP, median (IQR) & $8(6,10)$ & $10(7,10.5)$ & 0.17 \\
\hline & MAP, median (IQR) & $16.0(13.6,22.7)$ & $19.0(14.0,26.0)$ & 0.24 \\
\hline & Respiratory Rate/Hz, median (IQR) & $20(16,30)$ & $26.5(8,30)$ & 0.68 \\
\hline & FiO2 (\%), median (IQR) & $100(60,100)$ & $100(92.5,100)$ & 0.45 \\
\hline & SBP, median (IQR) & $80(60,100)$ & $70(53,91)$ & 0.56 \\
\hline & DBP, median (IQR) & $40(30,45)$ & $44(30,50)$ & 0.42 \\
\hline & MBP, median (IQR) & $51.5(38,60)$ & $53.5(38.5,62)$ & 0.96 \\
\hline \multirow[t]{3}{*}{ ECMO category } & Neonatal & $12(27 \%)$ & $9(25 \%)$ & 0.82 \\
\hline & Pediatric & $32(73 \%)$ & $27(75 \%)$ & \\
\hline & ECPR & $6(14 \%)$ & $12(33 \%)$ & $<0.001$ \\
\hline \multirow[t]{7}{*}{ ECMO support } & Veno-arterial only & $39(89 \%)$ & $35(97 \%)$ & 0.15 \\
\hline & Veno-arterial combined with venovenous & $5(11 \%)$ & $1(3 \%)$ & \\
\hline & Time to ECMO (hours) ${ }^{\mathbf{c}}$ & $7.00(1.41,45.00)$ & $2.81(1.00,13.68)$ & 0.13 \\
\hline & Central cannulation (initial) & $35(80 \%)$ & $22(61 \%)$ & 0.070 \\
\hline & ECMO flow day 1 (ml/kg/min), median (IQR) & $161(134,194)$ & $156(101,190)$ & 0.51 \\
\hline & ECMO support duration (days), median (IQR) & $4.9(3.7,8.2)$ & $1.7(0.5,7.1)$ & $<0.001$ \\
\hline & PICU length of stay (days), median (IQR) & $13.0(8.9,28.7)$ & $2.3(0.8,10.9)$ & $<0.001$ \\
\hline
\end{tabular}

$C P R$ cardiopulmonary resuscitation, $D B T$ diastolic arterial blood pressure, $E C M O$ extracorporeal life support, ECPR extracorporeal cardiopulmonary resuscitation, $M A P$ mean airway pressure, $M B P$ mean arterial blood pressure, $P E E P$ positive end-expiratory pressure, $P I C U$ pediatric intensive care unit, $P I M 2$ Pediatric Index of Mortality 2, PIP peak inspiratory pressure, SBP systolic arterial blood pressure

${ }^{a} p$ value based on two-sample Wilcoxon rank-sum (Mann-Whitney) test

${ }^{\mathrm{b}}$ First observation, the measure must be obtained within the first 60 min of PICU admission

${ }^{C}$ Time from PICU admission to ECMO cannulation 
Table 4 Uni- and multivariable prediction models for ICU mortality in 80 children treated with extracorporeal membrane oxygenation for septic shock

\begin{tabular}{|c|c|c|c|c|c|}
\hline \multicolumn{2}{|l|}{ Predictor variable } & \multicolumn{2}{|l|}{ Univariable model } & \multicolumn{2}{|c|}{ Multivariable model } \\
\hline Group & Predictor & OR $(95 \% \mathrm{Cl})$ & $p$ value & OR $(95 \%$ Cl) & $p$ value \\
\hline \multirow[t]{3}{*}{ Metabolic } & Lactate (mmol/l) & $1.21(1.06-1.38)$ & 0.004 & $1.21(1.04-1.40)$ & 0.012 \\
\hline & $\mathrm{pH}$ pre ECMO & $0.02(0.00-0.64)$ & 0.026 & NS & \\
\hline & HCO3- pre ECMO & $0.88(-0.79$ to 0.98$)$ & 0.017 & NS & \\
\hline Circulatory & Cardiac arrest pre-ECMO & $4.20(1.62-10.87)$ & 0.003 & $4.59(1.58-13.10)$ & 0.005 \\
\hline Severity & Pediatric Index of Mortality-2 & $1.24(0.98-1.57)$ & 0.079 & NS & \\
\hline \multirow[t]{2}{*}{ ECMO delivery } & Central cannulation & $0.40(0.15-1.09)$ & 0.074 & $0.31(0.10-0.98)$ & 0.046 \\
\hline & Flow at $4 \mathrm{~h}$ in $\mathrm{ml} / \mathrm{kg} / \mathrm{min}$ & $1.00(0.99-1.00)$ & 0.271 & NS & \\
\hline
\end{tabular}

$O R$ odds ratio, $C l$ confidence interval, SBP systolic blood pressure

the first hour of PICU admission may more accurately reflect real time decision-making and may possibly result in even higher discriminatory performance of the prediction tool. We acknowledge that a proportion of patients managed on ECMO for sepsis had undergone prior interhospital transfer, implying that the true duration from hospital admission to cannulation was underestimated in some. Fifth, while we manually checked the phenotype of ECMO cases against medical records to ensure criteria for shock, including inotrope treatment, were met prior to ECMO, the prospective databases accessed were not designed to investigate refractory septic shock. We did not have information available on pre-PICU treatment, including delays in intravenous antimicrobial therapy [38, 39], and timing of inotrope initiation. Sixth, we assessed all-cause mortality and did not analyze cause of death or underlying diseases, which may affect decisions to stop treatment in this patient group. Seventh, information on individual inotrope doses was not available, which potentially may have yielded additional discriminatory value as recently demonstrated in a multicenter study on refractory septic shock [9]. Finally, we did not collect data on long-term cognitive and behavioral outcomes which may be severely affected in sepsis survivors [40].

\section{Conclusions}

This large binational study indicates that ECMO is used in approximatively 1 out of 60 children admitted to PICU with sepsis and septic shock. We were able to demonstrate thresholds for survival benefit of ECMO using an easily available sepsis mortality prediction model. In our cohort, ECMO was unlikely to confer a survival benefit for children with sepsis and septic shock with below $47 \%$ predicted mortality. Our findings demonstrate that, given the rarity of ECMO therapy for septic shock at population level, a sufficiently powered randomized controlled trial to demonstrate ECMO survival benefit is unlikely to be feasible. Instead, future research should seek to enhance the precision of individual treatment benefit prediction through sequential assessment of the score. Applying dynamic information which integrates response to therapy during the first hours of ICU support will be of value as a further criterion to identify a trajectory towards cardiac arrest and death. In addition, future studies should test the application of our risk score for the purpose for benchmarking of mortality outcomes, quality improvement, and consideration for enrolment in trials of novel adjunctive therapies such as extracorporeal-based anti-inflammatory interventions [41].

\section{Supplementary information}

Supplementary information accompanies this paper at https://doi.org/10 1186/s13054-019-2685-1.

Additional file 1. Supplementary Methods.

Additional file 2. Kaplan-Meier time to death curve is shown ( $n=537$, panel C) out of 5,062 children admitted to ICU with sepsis/septic shock.

Additional file 3. Pathogens identified in 5,062 children admitted to Intensive Care Units with sepsis and septic shock compared between children receiving veno-arterial Extracorporeal Membrane Oxygenation (ECMO) and controls (no ECMO).

Additional file 4. Demographic and microbiological characteristics of 80 children with sepsis and septic shock treated with veno-arterial Extracorporeal Membrane Oxygenation (ECMO) compared between children who survived and children that died.

Additional file 5. Distribution of predicted mortality.

Additional file 6. Sensitivity analysis to estimating treatment benefit for children with septic shock treated with Extracorporeal life support (ECMO, $n=80$ ) versus controls ( $n=2347$ ), restricted to patients coded as septic shock in the ANZPIC registry.

Additional file 7. Extracorporeal Membrane Oxygenation (ECMO) flow rates measured at 4 hours (in $\mathrm{ml} / \mathrm{kg} / \mathrm{min}$ ) post cannulation in $n=80$ children treated with veno-arterial ECMO for septic shock. Flow rates are compared between children that underwent peripheral cannulation ( $n=$ $23)$ versus children that underwent central cannulation $(n=57)$, split into those that survived $(n=44)$ and that died $(n=36)$.

\section{Abbreviations}

ECMO: Extracorporeal membrane oxygenation; OR: Odds ratio; PICU: Pediatric intensive care unit; PIM: Pediatric Index of Mortality; SSC: Surviving Sepsis Campaign; VA: Veno-arterial; W: Venovenous

\section{Acknowledgements}

We thank the Paediatric Study Group of the Australian and New Zealand Intensive Care Society for supporting this study. We also thank the 
intensivists, data managers, and other staff in the participating ICUs for their data contributions. The ANZPIC Registry is one of the four registries managed by the Australian and New Zealand Intensive Care Society's Centre for Outcome and Resource Evaluation (ANZICS CORE). ANZICS CORE is supported by the Ministry of Health (New Zealand) and State and Territory Health Departments (Australia).

We thank the ECMO coordinators, ECMO teams, and ECMO boards at the study sites for their support, especially Derek Best, Royal Children's Hospital Melbourne; Katherine Griffiths, Perth Children's Hospital; Amelia Griffiths, Westmead Children's Hospital; and Emma Haisz, Queensland Children's Hospital.

Paediatric Study Group of the Australian and New Zealand Intensive Care Society:

Anusha Ganeshalingam, Claire Sherring, Starship Children's Hospital, Auckland, New Zealand; Simon Erickson, Samantha Barr, Perth Children's Hospital, Perth, Australia; Andreas Schibler, Debbie Long, Luregn Schlapbach (Chair), Jan Alexander (ANZPIC registry), Queensland Children's Hospital, Brisbane, Australia; Shane George, Gold Coast University Hospital; Gary Williams, Vicky Smith, Sydney Children's Hospital, Randwick, Australia; Warwick Butt, Carmel Delzoppo, Johnny Millar (ANZPIC registry lead), Ben Gelbart (Vice Chair), Royal Children's Hospital, Melbourne, Australia; Felix Oberender, Monash Children`s Hospital, Melbourne, Australia; Subodh Ganu, Georgia Letton, Women's and Children's Hospital, Adelaide, Australia; Jonathan Egan, Gail Harper, Marino Festa (Past Chair), Westmead Children's Hospital, Sydney, Australia.

\section{Authors' contributions}

LJS designed the study, performed the initial analyses, interpreted the data, and wrote the first draft and the final manuscript. LS performed the statistical analyses and contributed to the manuscript writing. WB and GM were involved in the study design, data interpretation, and manuscript writing. RC, DA, and MF collected the data and were involved in the data interpretation and manuscript writing. All authors read and approved the final manuscript.

\section{Funding}

LJS is supported by a Practitioner Fellowship of the National Health and Medical Research Council of Australia and New Zealand and by the Children's Hospital Foundation, Brisbane, Australia.

\section{Availability of data and materials}

The data that support the findings of this study are available from the Australian and New Zealand Paediatric Intensive Care (ANZPIC) Registry, but restrictions apply to the availability of these data, which were used under license for the current study, and so are not publicly available.

\section{Ethics approval and consent to participate}

The study was approved by the Human Research and Ethics Committee (Mater Health Services HREC, Brisbane, Australia) including waiver of informed consent (HREC/13/MHS/153).

\section{Consent for publication}

Not applicable.

\section{Competing interests}

The authors declare that they have no competing interests.

\section{Author details}

${ }^{1}$ Paediatric Critical Care Research Group, Child Health Research Centre, The University of Queensland, Brisbane, Australia. ${ }^{2}$ Paediatric Intensive Care Unit, Queensland Children's Hospital, South Brisbane, QLD 4101, Australia. ${ }^{3}$ Department of Pediatrics, Inselspital, Bern University Hospital, University of Bern, Bern, Switzerland. ${ }^{4}$ University of Melbourne, Melbourne, Australia. ${ }^{5}$ Paediatric Intensive Care Unit, The Royal Children's Hospital, Melbourne, Australia. ${ }^{6}$ Department of Epidemiology and Preventive Medicine, Monash University, Melbourne, Australia. ${ }^{7}$ Paediatric Intensive Care Unit, Children's Hospital Westmead, Sydney, Australia. ${ }^{8}$ Kids Critical Care Research Group, Kids Research, Sydney Children's Hospitals Network, Sydney, Australia. ${ }^{9}$ Paediatric Intensive Care Unit, Perth Children's Hospital, Perth, Australia.

${ }^{10}$ Cardiothoracic Intensive Care Unit, National University Health System,

Singapore, Singapore.
Received: 25 August 2019 Accepted: 26 November 2019

Published online: 30 December 2019

\section{References}

1. Schlapbach LJ, Straney L, Alexander J, MacLaren G, Festa M, Schibler A, Slater A, Group APS. Mortality related to invasive infections, sepsis, and septic shock in critically ill children in Australia and New Zealand, 2002-13: a multicentre retrospective cohort study. Lancet Infect Dis. 2015;15(1):46-54.

2. Weiss SL, Fitzgerald JC, Pappachan J, Wheeler D, Jaramillo-Bustamante JC, Salloo A, Singhi SC, Erickson S, Roy JA, Bush JL, et al. Global epidemiology of pediatric severe sepsis: the sepsis prevalence, outcomes, and therapies study. Am J Respir Crit Care Med. 2015;191(10):1147-57.

3. Fleischmann-Struzek C, Goldfarb DM, Schlattmann P, Schlapbach LJ, Reinhart K, Kissoon N. The global burden of paediatric and neonatal sepsis: a systematic review. Lancet Respir Med. 2018;6(3):223-30.

4. Dellinger RP, Levy MM, Rhodes A, Annane D, Gerlach H, Opal SM, Sevransky JE, Sprung CL, Douglas IS, Jaeschke R, et al. Surviving Sepsis Campaign: international guidelines for management of severe sepsis and septic shock, 2012. Intensive Care Med. 2013;39(2):165-228.

5. Davis AL, Carcillo JA, Aneja RK, Deymann AJ, Lin JC, Nguyen TC, OkhuysenCawley RS, Relvas MS, Rozenfeld RA, Skippen PW, et al. American College of Critical Care Medicine Clinical Practice Parameters for hemodynamic support of pediatric and neonatal septic shock. Crit Care Med. 2017;45(6): 1061-93.

6. Angus DC, van der Poll T. Severe sepsis and septic shock. N Engl J Med. 2013:369(9):840-51.

7. Hotchkiss RS, Karl IE. The pathophysiology and treatment of sepsis. N Engl J Med. 2003;348(2):138-50.

8. Weiss SL, Balamuth F, Hensley J, Fitzgerald JC, Bush J, Nadkarni VM, Thomas NJ, Hall M, Muszynski J. The epidemiology of hospital death following pediatric severe sepsis: when, why, and how children with sepsis die. Pediatr Crit Care Med. 2017;18(9):823-30.

9. Morin L, Ray S, Wilson C, Remy S, Benissa MR, Jansen NJG, Javouhey E Peters MJ, Kneyber M, De Luca D, et al. Refractory septic shock in children: a European Society of Paediatric and Neonatal Intensive Care definition. Intensive Care Med. 2016;42(12):1948-57.

10. MacLaren G, Butt W, Best D, Donath S. Central extracorporeal membrane oxygenation for refractory pediatric septic shock. Pediatr Crit Care Med. 2011;12(2):133-6.

11. Horton S, d'Udekem Y, Shann F, Butt W, Bennett M, Best D, Brizard C. Extracorporeal membrane oxygenation via sternotomy for circulatory shock. J Thorac Cardiovasc Surg. 2010;139(2):e12-3.

12. Maclaren G, Butt W, Best D, Donath S, Taylor A. Extracorporeal membrane oxygenation for refractory septic shock in children: one institution's experience. Pediatr Crit Care Med. 2007:8(5):447-51.

13. Fortenberry JD, Paden ML. Extracorporeal therapies in the treatment of sepsis: experience and promise. Semin Pediatr Infect Dis. 2006;17(2):72-9.

14. MacLaren G, Pellegrino V, Butt W, Preovolos A, Salamonsen R. Successful use of ECMO in adults with life-threatening infections. Anaesth Intensive Care 2004;32(5):707-10.

15. Lin YC, Ma JY, Yeh SJ, Chiu KM, Chu SH. Use of extracorporeal membrane oxygenation to rescue a newborn with early-onset group B streptococcal sepsis and cardiopulmonary failure. J Formos Med Assoc. 2004;103(1):67-70.

16. Luyt DK, Pridgeon J, Brown J, Peek G, Firmin R, Pandya HC. Extracorporeal life support for children with meningococcal septicaemia. Acta Paediatr. 2004;93(12):1608-11

17. Goldman AP, Kerr SJ, Butt W, Marsh MJ, Murdoch IA, Paul T, Furnin RK Tasker RC, Macrae DJ. Extracorporeal support for intractable cardiorespiratory failure due to meningococcal disease. Lancet. 1997: 349(9050):466-9.

18. Beca J, Butt W. Extracorporeal membrane oxygenation for refractory septic shock in children. Pediatrics. 1994;93(5):726-9.

19. Hocker JR, Simpson PM, Rabalais GP, Stewart DL, Cook LN. Extracorporeal membrane oxygenation and early-onset group B streptococcal sepsis. Pediatrics. 1992;89(1):1-4

20. McCune S, Short BL, Miller MK, Lotze A, Anderson KD. Extracorporeal membrane oxygenation therapy in neonates with septic shock. J Pediatr Surg. 1990;25(5):479-82.

21. Schlapbach LJ, MacLaren G, Festa M, Alexander J, Erickson S, Beca J, Slater A, Schibler A, Pilcher D, Millar J, et al. Prediction of pediatric sepsis mortality within 1 h of intensive care admission. Intensive Care Med. 2017:43(8):1085-96. 
22. Straney L, Clements A, Parslow RC, Pearson G, Shann F, Alexander J, Slater A, Group APS, the Paediatric Intensive Care Audit N. Paediatric index of mortality 3: an updated model for predicting mortality in pediatric intensive

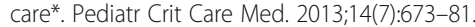

23. Goldstein B, Giroir B, Randolph A, International Consensus Conference on Pediatric S. International pediatric sepsis consensus conference: definitions for sepsis and organ dysfunction in pediatrics. Pediatr Crit Care Med. 2005;6(1):2-8.

24. Slater A, Shann F, Pearson G, Paediatric Index of Mortality Study G. PIM2: a revised version of the Paediatric Index of Mortality. Intensive Care Med. 2003;29(2):278-85.

25. Haque IU, Zaritsky AL. Analysis of the evidence for the lower limit of systolic and mean arterial pressure in children. Pediatr Crit Care Med. 2007:8(2):138-44.

26. Cvetkovic M, Lutman D, Ramnarayan P, Pathan N, Inwald DP, Peters MJ. Timing of death in children referred for intensive care with severe sepsis: implications for interventional studies. Pediatr Crit Care Med. 2015;16(5):410-7.

27. Agyeman PKA, Schlapbach $\amalg$, Giannoni E, Stocker M, Posfay-Barbe KM, Heininger U, Schindler M, Korten I, Konetzny G, Niederer-Loher A, et al. Epidemiology of blood culture-proven bacterial sepsis in children in Switzerland: a population-based cohort study. Lancet Child Adolesc Health. 2017:1(2):124-33.

28. Schmidt M, Bailey M, Sheldrake J, Hodgson C, Aubron C, Rycus PT, Scheinkestel C, Cooper DJ, Brodie D, Pellegrino V, et al. Predicting survival after extracorporeal membrane oxygenation for severe acute respiratory failure. The Respiratory Extracorporeal Membrane Oxygenation Survival Prediction (RESP) score. Am J Respir Crit Care Med. 2014;189(11):1374-82.

29. Barbaro RP, Boonstra PS, Paden ML, Roberts LA, Annich GM, Bartlett RH, Moler FW, Davis MM. Development and validation of the pediatric risk estimate score for children using extracorporeal respiratory support (PedRESCUERS). Intensive Care Med. 2016;42(5):879-88.

30. Boeddha NP, Schlapbach L, Driessen GJ, Herberg JA, Rivero-Calle I, CebeyLopez M, Klobassa DS, Philipsen R, de Groot R, Inwald DP, et al. Mortality and morbidity in community-acquired sepsis in European pediatric intensive care units: a prospective cohort study from the European Childhood Life-threatening Infectious Disease Study (EUCLIDS). Crit Care. 2018:22(1):143.

31. MacLaren G, Butt W, Best D. Pediatric septic shock guidelines and extracorporeal membrane oxygenation management. Crit Care Med. 2009; 37(6):2143-4 author reply 2144-2145.

32. Ruth A, McCracken CE, Fortenberry JD, Hebbar KB. Extracorporeal therapies in pediatric severe sepsis: findings from the pediatric health-care information system. Crit Care. 2015;19:397.

33. Oberender F, Ganeshalingham A, Fortenberry JD, Hobson MJ, Houmes RJ, Morris KP, Numa A, Hoq MM, Donath S, Beca J, et al. Venoarterial extracorporeal membrane oxygenation versus conventional therapy in severe pediatric septic shock. Pediatr Crit Care Med. 2018;19(10):965-72.

34. Maclaren G, Butt W. Extracorporeal membrane oxygenation and sepsis. Crit Care Resuscitation. 2007;9(1):76-80.

35. Moynihan KM, Alexander PMA, Schlapbach LJ, Millar J, Jacobe $S$ Ravindranathan H, Croston EJ, Staffa SJ, Burns JP, Gelbart B. Australian and New Zealand Intensive Care Society Pediatric Study Group (ANZICS PSG) and the ANZICS Centre for Outcome and Resource Evaluation (ANZICS CORE). Intensive Care Med. 2019;45(9):1262-71.

36. Schlapbach $L$, MacLaren G. Targeting Staphylococcus aureus in Pediatric Surviving Sepsis Bundles. JAMA Pediatr. 2017:171(3):301.

37. Smith S, Butt W, Best D, MacLaren G. Long-term survival after extracorporeal life support in children with neutropenic sepsis. Intensive Care Med. 2016; 42(5):942-3.

38. Weiss SL, Fitzgerald JC, Balamuth F, Alpern ER, Lavelle J, Chilutti M, Grundmeier R, Nadkarni VM, Thomas NJ. Delayed antimicrobial therapy increases mortality and organ dysfunction duration in pediatric sepsis. Crit Care Med. 2014;42(11):2409-17.

39. Launay E, Gras-Le Guen C, Martinot A, Assathiany R, Martin E, Blanchais T, Deneux-Tharaux C, Roze JC, Chalumeau M. Why children with severe bacterial infection die: a population-based study of determinants and consequences of suboptimal care with a special emphasis on methodological issues. PLoS One. 2014;9(9):e107286.
40. Kachmar AG, Irving SY, Connolly CA, Curley MAQ. A systematic review of risk factors associated with cognitive impairment after pediatric critical illness. Pediatr Crit Care Med. 2018;19(3):e164-71.

41. Ankawi G, Neri M, Zhang J, Breglia A, Ricci Z, Ronco C. Extracorporeal techniques for the treatment of critically ill patients with sepsis beyond conventional blood purification therapy: the promises and the pitfalls. Crit Care. 2018;22(1):262.

\section{Publisher's Note}

Springer Nature remains neutral with regard to jurisdictional claims in published maps and institutional affiliations.
Ready to submit your research? Choose BMC and benefit from:

- fast, convenient online submission

- thorough peer review by experienced researchers in your field

- rapid publication on acceptance

- support for research data, including large and complex data types

- gold Open Access which fosters wider collaboration and increased citations

- maximum visibility for your research: over $100 \mathrm{M}$ website views per year

At BMC, research is always in progress.

Learn more biomedcentral.com/submissions 